\title{
Impact of Bedside Combined Cardiopulmonary Ultrasound on Etiological Diagnosis and Treatment of Acute Respiratory Failure in Critically Ill Patients
}

\author{
Bapi Barman ${ }^{1}$, Anit Parihar ${ }^{2}$, Neera Kohli ${ }^{3}$, Avinash Agarwal ${ }^{4}$, Durgesh K Dwivedi ${ }^{5}$, Gangotri Kumari ${ }^{6}$
}

\begin{abstract}
Aims and objectives: To prospectively evaluate the impact of cardiopulmonary ultrasound (CPUS) on etiological diagnosis and treatment of critically ill acute respiratory failure (ARF) patients.

Design: This is a prospective observational study conducted in a general intensive care unit (ICU) of a tertiary care center in India. Patients over 18 years old with presence of one of the objective criteria of ARF. Patients either consecutively admitted for ARF to ICU or already admitted to ICU for a different reason but later developed ARF during their hospital stay. Written informed consent in local language was obtained from next of kin. Interventions: All included patients underwent bedside CPUS including lung ultrasound (US) and transthoracic echocardiography plus targeted venous US by single investigator, blinded to clinical data. The US diagnosis of ARF etiology was shared with treating intensivist. Initial clinical diagnosis (ICD) and treatment plan (made before US) of each patient were compared with post-US clinical diagnosis and treatment plan. The changes in diagnosis and treatment up to 24 hours post-US were considered as impact of US.

Results: Mean age of 108 included patients was $45.7 \pm 20.4$ years (standard deviation). The ICD was correct in $67.5 \%$ (73/108) cases, whereas the combined CPUS yielded correct etiological diagnosis in 88\% (95/108) cases. Among the 108 included patients, etiological diagnosis of ARF was altered after CPUS in 40 (37\%) patients, which included "diagnosis changed" in 18 (17\%) and "diagnosis added" in 22 (20\%). Treatment plan was changed in 39 (36\%) patients after CPUS, which included surgical interventions in 17 (16\%), changes in medical therapy in 12 (11\%), and changes in ventilation strategy in $4(3.5 \%)$ patients.

Conclusion: This study demonstrates that use of combined US approach as an initial test in ARF, improves diagnostic accuracy for identification of underlying etiology, and frequently changes clinical diagnosis and/or treatment.

Keywords: Acute respiratory failure, Combined ultrasound approach, Critical care, Impact assessment, Lung ultrasound, Transthoracic echocardiography.

Indian Journal of Critical Care Medicine (2020): 10.5005/jp-journals-10071-23661
\end{abstract}

\section{INTRODUCTION}

Acute respiratory failure (ARF) is a life-threatening condition that results from acute impairment in gas exchange between lungs and blood resulting in hypoxia with or without hypercapnia. ${ }^{1}$ Around half of all admitted patients in intensive care unit (ICU) suffer from $\mathrm{ARF}^{2}$ which is associated with $30-65 \%$ mortality rates..$^{2-7}$ There are multiple causes of ARF, which can be grouped as respiratory and nonrespiratory causes. Early diagnosis of etiological factor(s) and appropriate therapeutic strategy is essential to improve outcome of ARF patients. ${ }^{8}$

Diagnosis of etiological factor of ARF is challenging for physicians. Traditionally, physical examination, arterial blood gas (ABG) analysis, bedside radiography, and computed tomography (CT) are used. Physical examination has low accuracy, ${ }^{9,10}$ while ABG analysis provides limited information about etiology of ARF. ${ }^{11}$ Bedside chest X-rays (CXRs) has low diagnostic efficacy. ${ }^{9}$ Although diagnostic accuracy of CT is high, CT in critically ill patients has several limitations such as risk of radiation exposure, high cost, and moving critically ill patients to scanning room can be associated with inadvertent extubations.

Bedside ultrasound (US) is now emerging as a valuable tool in dynamic assessment of lungs and hemodynamic status. Bedside US is readily available, noninvasive, convenient, and cost effective can be repeated at will and has shown better diagnostic efficacy
1-3,5,6 Department of Radiodiagnosis, King George's Medical University, Lucknow, Uttar Pradesh, India

${ }^{4}$ Department of Critical Care Medicine, King George's Medical University, Lucknow, Uttar Pradesh, India

Corresponding Author: Anit Parihar, Department of Radiodiagnosis, King George's Medical University, Lucknow, Uttar Pradesh, India, Phone: +91 9455519593, e-mail: anitparihar@gmail.com

How to cite this article: Barman B, Parihar A, Kohli N, Agarwal A, Dwivedi DK, Kumari G. Impact of Bedside Combined Cardiopulmonary Ultrasound on Etiological Diagnosis and Treatment of Acute Respiratory Failure in Critically III Patients. Indian J Crit Care Med 2020;24(11):1062-1070.

Source of support: Nil

Conflict of interest: None

compared to physical examination and CXR for diagnosis of lung conditions in critically ill patients. ${ }^{9,10,12}$

There have been several studies in the field of point of care US for assessment of ARF patients in ICU and emergency settings. Few studies showed potential of combining lung ultrasound (LUS) and transthoracic echocardiography (TTE) as a single integrated assessment method for etiological diagnosis of ARF in ICU. ${ }^{13,14}$ These studies have limited applicability in clinical practice due

(c) The Author(s). 2020 Open Access This article is distributed under the terms of the Creative Commons Attribution 4.0 International License (https://creativecommons. org/licenses/by-nc/4.0/), which permits unrestricted use, distribution, and non-commercial reproduction in any medium, provided you give appropriate credit to the original author(s) and the source, provide a link to the Creative Commons license, and indicate if changes were made. The Creative Commons Public Domain Dedication waiver (http://creativecommons.org/publicdomain/zero/1.0/) applies to the data made available in this article, unless otherwise stated. 
Impact of Bedside Combined CPUS on Etiological Diagnosis and Treatment of ARF in Critically Ill Patients

to some important limitations, such as none of the studies reported acute respiratory distress syndrome (ARDS), which is quite surprising, as ARDS is considered a common cause of ARF. ${ }^{15}$ Therefore, results of these studies may not be applicable in cohorts where ARDS is prevalent. Till now only few studies have reported therapeutic impact of combined US approach in ICU. ${ }^{16,17}$ However, to our knowledge, specific data focusing on therapeutic impact of combined US approach in ARF patients is lacking.

The aim of our study was to prospectively evaluate the impact of bedside cardiopulmonary ultrasound (CPUS) on etiological diagnosis and treatment plan of critically ill ARF patients.

\section{Material and Methods}

\section{Study Design and Patients}

This prospective observational study was conducted with approval from Institutional Ethics Committee of King George's Medical University (Ref. code: 90th ECM II B-Thesis/PI). We prospectively recruited patients admitted to an ICU during September 2017 to August 2018. Patients were either consecutively admitted for ARF to ICU, or already admitted to ICU for a different reason but later developed ARF during their hospital stay. Any patients aged $\geq 18$ years with one of the objective criteria of ARF, including oxygen saturation by pulse oximetry $\left(\mathrm{SaO}_{2}\right) \leq 90 \%$ while breathing room air, $\mathrm{PaO}_{2} / \mathrm{FiO}_{2}$ ratio of $\leq 200 \mathrm{~mm} \mathrm{Hg}$, respiratory rate of $\geq 25 /$ minute, $\mathrm{PaCO}_{2}$ of $>45 \mathrm{~mm} \mathrm{Hg}$ with an arterial $\mathrm{pH}<7.35$, were included and screened for exclusion criteria (Table 1). Written informed consent in local language was obtained from next of kin of all participants.

\section{Lung and Cardiac Ultrasound}

All included patients underwent bedside combined CPUS including LUS and focused TTE by single investigator (B. Barman). The investigator was blinded to clinical data, and had no role in decision-making or clinical management of patients. Scans were performed with My Lab ${ }^{\mathrm{TM}}$ Seven (Esaote, Italy) US machine, using 3-10 MHz microconvex array, 3-5 MHz convex array, and 3-12 MHz linear array probes for LUS and 1-4 MHz phased array probe for TTE.

For LUS scanning, eight region/zone methods ${ }^{18,19}$ were used which included scanning of anterior and lateral chest wall on both sides with patients in supine $(n=92)$ or semirecumbent position. TTE was performed by taking 5-10 seconds acquisitions of following: parasternal long axis (PLAX), parasternal short axis views, apical four-chamber (A4C) views, and subcostal four-chamber views. LUS and echocardiography results were interpreted using standardized criteria for etiological diagnosis of ARF, as depicted in Table 2. After CPUS, venous US scan of lower extremity for deep venous thrombosis (DVT) was done with a linear probe, in a proportion of included patients ( $n=55,51 \%$ ) suspected for pulmonary embolism (PE) on US. PE was suspected on US after ruling out cardiogenic pulmonary edema, ARDS, and pneumothorax on CPUS; or in cases showing (a) presence of wedge shaped or rounded pleura-based hypoechoic consolidation on LUS; (b) A-profile or C-profile on LUS; or (c) acute RV dysfunction on TTE. The scans were performed without interrupting management within 24 hours of ICU admission or developing ARF (average $8 \pm 5$ hours). Average scan time was $15 \pm 6$ minutes per case. Imaging data were recorded for further assessment. The US performance bias of the investigator was reduced by quality assurance check on recorded images by an independent observer, who checked for interpretability of images obtained and that the correct diagnosis was made.
Table 1: Inclusion and exclusion criteria of patients

\begin{tabular}{|c|c|}
\hline $\begin{array}{l}\text { Inclusion criteria: Age } \geq 18 \text { years } \\
\text { and presence of one of the } \\
\text { following objective criteria of } \\
\text { acute respiratory failure (ARF) }\end{array}$ & $\begin{array}{l}\text { Exclusion criteria: Any patient with } \\
\text { one of the following known condi- } \\
\text { tion was excluded }\end{array}$ \\
\hline $\begin{array}{ll}\text { - } & \text { An oxygen saturation } \\
\left(\mathrm{SaO}_{2}\right) \text { as measured by pulse } \\
\text { oximetry of } \leq 90 \% \text { while } \\
\text { breathing room air } \\
\text { - } \mathrm{A} \mathrm{PaO}_{2} / \mathrm{FiO}_{2} \text { ratio of } \leq 200 \\
\mathrm{~mm} \mathrm{Hg} \\
\text { A respiratory rate of } \geq 25 / \\
\text { minute } \\
\text { - } \mathrm{AaO} \text { of } \leq 60 \mathrm{~mm} \mathrm{Hg}, \text { and } / \\
\text { or a PaCO of }>45 \mathrm{~mm} \mathrm{Hg} \\
\text { with an arterial } \mathrm{pH}<7.35\end{array}$ & $\begin{array}{ll}\text { - } & \text { Intrathoracic malignancy } \\
\text { - Severe chest wall/bony } \\
\text { spinal abnormalities } \\
\text { - Known neuromuscular } \\
\text { disorders } \\
\text { - Known interstitial lung } \\
\text { disease } \\
\text { - Spinal injury or head injury } \\
\text { with hemorrhagic mass } \\
\text { effect } \\
\text { - Patient with } \\
\text { pneumonectomy } \\
\text { - Hypovolemic shock with } \\
\text { decreased pulmonary } \\
\text { perfusion } \\
\text { - Diaphragmatic dysfunction } \\
\text { - Patient with massive pleural } \\
\text { effusion } \\
\text { - Patient with no final } \\
\text { diagnosis } \\
\text { Patient with multiple } \\
\text { etiological diagnosis for ARF }\end{array}$ \\
\hline
\end{tabular}

The investigator followed the methodology as depicted in Table 3. The primary outcome was any change in initial clinical diagnosis (ICD) and/or treatment plan after combined CPUS. For this, ICD and treatment plans of each patient were compared with post-US clinical diagnosis and treatment plan. "ICD and treatment plan" was defined as etiological diagnosis and treatment plan of ARF made by primary treating intensivist before US test on day 1 ; utilizing patient's history, physical examination, chest radiography, and available emergency laboratory tests. "Post-US clinical diagnosis and treatment plan" was defined as etiological diagnosis of ARF and treatment plan made by treating intensivist after US test, utilizing all the clinical data available before US scan plus US data. The changes in diagnosis and treatment plans up to 24 hours post-US scan were considered as impact of US. The following changes in treatment plan after US scan were taken as impact of CPUS test: (a) surgical interventions including drainage of pleural effusion (thoracentesis) under US guidance, intercostal chest tube (ICT) placement for pneumothorax; (b) changes in ventilation strategy including use of lung protective ventilation, escalation from noninvasive ventilation (NIV) to invasive mechanical ventilation (IMV) or downgrading from IMV to NIV; (c) changes in medical therapy including restriction/escalation of fluid therapy, addition/removal of diuretics, inotropes, and use of thrombolytic/anticoagulants for treatment of PE. However, vasopressor use was not taken as impact of US.

\section{Final Etiological Diagnosis of Acute Respiratory Failure}

Final etiological diagnosis (FD) of ARF in all patients was obtained from the final clinical diagnosis on day 7 (assuming the day of US test as day 1). FD was made by a team comprising of three senior intensivists. Their FD was made on basis of complete clinical history and examinations, laboratory investigations, chest radiography and US data, chest CT (done in 49 or $45 \%$ patients), response to treatment, and independent TTE by a cardiologist whenever indicated (done in 
Table 2: Ultrasound signs and profiles used for etiological diagnosis of ARF

\begin{tabular}{|c|c|c|}
\hline Condition & Lung ultrasound signs & TTE signs \\
\hline Pneumonia ${ }^{12,14,20,21}$ & $\begin{array}{l}\text { - Unilateral anterior or posterolateral alveolar consolidation } \\
\text { (C-profile) or } \\
\text { - Unilateral multiple B-lines with predominant A-lines on } \\
\text { other side (A/B-profile) } \\
\text { - } \pm \text { Pleural effusion or PLAPS (posterolateral alveolar } \\
\text { consolidation and/or pleural syndrome) }\end{array}$ & - Nonspecific \\
\hline $\begin{array}{l}\text { Hydrostatic or cardiogenic } \\
\text { pulmonary edema }{ }^{22-24}\end{array}$ & $\begin{array}{l}\text { Diffuse bilateral anterior B-lines (B-profile) associated with } \\
\text { lung sliding and normal pleural line } \\
\text { - } \pm \text { Less than } 3 \text { subpleural consolidations in nondependent } \\
\text { lung areas }\end{array}$ & $\begin{array}{l}\text { - Left ventricular (LV) diastolic } \\
\text { dysfunction } \\
\text { - } \pm \text { LV systolic dysfunction }\end{array}$ \\
\hline $\begin{array}{l}\text { Nonhydrostatic pulmonary } \\
\text { edema or } \operatorname{ARDS}^{22,25,26}\end{array}$ & $\begin{array}{l}\text { - Diffuse bilateral anterior B-lines (B-profile) associated with } \\
\text { any one of the following: } \\
\text { - Pleural line irregularities } \\
\text { - } \geq 3 \text { subpleural consolidations in nondependent lung areas }\end{array}$ & $\begin{array}{l}\text { - Normal LV diastolic function } \\
\pm \text { Right ventricular (RV) dysfunction }\end{array}$ \\
\hline Pneumothorax ${ }^{27-30}$ & $\begin{array}{l}\text { - Anterior A-lines with absent anterior lung sliding (A-profile) } \\
\text { and } \\
\text { - Presence of lung point }\end{array}$ & - Nonspecific \\
\hline $\begin{array}{l}\text { Acute bronchospasm (de- } \\
\text { compensated COPD or acute } \\
\text { asthma) }{ }^{12,13}\end{array}$ & $\begin{array}{l}\text { - Bilateral predominant A-lines with present lung sliding } \\
\text { without any pleural effusion or PLAPS (A-or normal profile) } \\
\text { - Absence of DVT }\end{array}$ & $\begin{array}{l}\text { - Chronic RV dysfunction } \\
\text { or } \\
\text { - Nonspecific }\end{array}$ \\
\hline Pulmonary embolism ${ }^{31-34}$ & $\begin{array}{l}\text { - } \geq 2 \text { wedge shaped or rounded pleura-based hypoechoic } \\
\text { consolidations or } \\
\text { - } 1 \text { wedge shaped or rounded pleura-based hypoechoic } \\
\text { consolidation with presence of DVT or } \\
\text { - A profile with presence of DVT } \\
\text { - } \pm \text { Pleural effusion. }\end{array}$ & $\begin{array}{l}\text { - Acute RV dysfunction } \\
\text { or } \\
\text { - Nonspecific }\end{array}$ \\
\hline
\end{tabular}

TTE assessment methods:

a) Visual estimation of left ventricular ejection fraction (LVEF) was done on PLAX and A4C views, as $<30 \%, 30 \%$ to $<50 \%$, and $\geq 50 \%$. LVEF $<50 \%$ was considered as systolic dysfunction ${ }^{14,17,35}$

b) LV diastolic dysfunction was considered in cases of elevated left ventricular filling pressure (LVFP). LVFP was estimated using pulsedwave and tissue Doppler of mitral inflow and lateral annulus, following standard guidelines and recommendations s $^{13,36,37}$

c) On visual estimation, acute RV dysfunction was considered when there was RV dilatation and/or abnormal inter-ventricular septal configuration. Chronic RV dysfunction was considered when there was RV hypertrophy without RV dilatation or abnormal septal configuration ${ }^{13,37,38}$

d) Presence of mitral valve disease (MVD) was evaluated using color Doppler for reverse flow indicating mitral regurgitation (MR) and visual assessment of the mitral valve for reduced leaflet movement indicating mitral stenosis (MS)

e) Presence and size of pericardial effusion was also evaluated

21 or 19\% patients). Standard guidelines and tests were evaluated for FD (Table 4). The main diagnoses finally proposed were pneumonia ( $n=34$, including community and hospital acquired pneumonias, ventilator-associated pneumonia); hydrostatic or cardiogenic pulmonary edema $(n=22)$; nonhydrostatic pulmonary edema or ARDS $(n=19)$; acute bronchospasm $[n=13$, including cases of decompensated chronic obstructive pulmonary disease (COPD) and acute asthma], pneumothorax $(n=12)$, and PE $(n=8)$.

\section{Statistical Analysis}

Statistical analysis was performed using SPSS statistics V23 (IBM SPSS Inc, Chicago, IL, USA). We calculated our sample size based on the outcome of assessing diagnostic accuracy of bedside CPUS to accurately assess the common causes of ARF in critically ill patients. We calculated sample size of 108 ARF patients to yield a minimum $80 \%$ sensitivity and $80 \%$ power with type I error $(\alpha)=0.05$.

\section{Results}

\section{Participant Characteristics}

Out of the 123 patients with ARF enrolled in the study over 1-year period, final diagnosis was not established in four patients because of unknown diagnosis at the end of seventh day of hospitalization, five patients had multiple etiological diagnoses for ARF, and two patients had miscellaneous diagnoses (Table 4). US scan was not possible or incomplete in four patients due to thoracotomy, subcutaneous emphysema, or inadequate sonographic window. These 15 patients were subsequently excluded from the analysis. So a total of 108 patients were considered for analysis.

Age of patients ranged from 18 to 87 years with a mean age of $45.7 \pm 20.4$ years (standard deviation). At the time of inclusion, patients had a mean $\mathrm{PaO}_{2} / \mathrm{FiO}_{2}$ ratio of $142 \pm 53$ (range 56-200). About 78 of 108 (72\%) patients were intubated at the time of 
Table 3: Methodology and flow diagram of events

Admission to ICU with ARF or developed ARF while admitted in ICU

Day $1 \quad$ Investigator performed CPUS scan on patients admitted with ARF or developed ARF within last 24 hours, and documented US findings and etiological diagnosis of ARF and shared it with treating intensivist

\section{$\downarrow$}

Investigator then recorded the ICD and treatment plan of these patient from the treatment chart

$\downarrow$

Day 2 On the next day investigator did CPUS scan on subsequent patients with $A R F^{b}$ and shared US data with treating intensivist

$$
\downarrow
$$

Investigator then recorded the ICD and treatment plan of the patients, who were scanned on the same day; and also recorded the postultrasound clinical diagnosis and treatment plan of those patients, who were scanned on the previous day$$
\downarrow
$$

Day 7 Final etiological diagnosis (FD) was recorded from the treatment plan

Same events were repeated during the study period for all the included patient

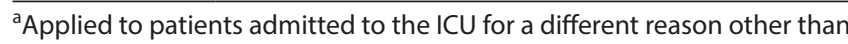
ARF but subsequently developed ARF during ICU stay

${ }^{\mathrm{b}}$ These are new patients admitted with ARF or developed ARF, since after the investigator left the ICU on previous day; and also within the last 24 hours time period inclusion. Out of 108 patients, 68 (63\%) were males and remaining 40 (37\%) were females.

\section{Diagnostic Accuracy}

Accuracy of two diagnostic approaches, ICD and combined CPUS diagnosis were compared against the final diagnosis. The ICD was correct in $68 \%(73 / 108)$ cases, whereas the focused CPUS test yielded a correct etiological diagnosis in 88\% (95/108) cases (Fig. 1). Sensitivity and specificity of CPUS for each etiological entity were as follows: $88 \%$ and $92 \%$ for pneumonia; $95 \%$ and $98 \%$ for cardiogenic pulmonary edema; $89 \%$ and $97 \%$ for ARDS; $83 \%$ and $100 \%$ for pneumothorax; $85 \%$ and $99 \%$ for decompensated COPD/acute asthma; and $75 \%$ and $99 \%$ for PE. CPUS findings in a case of ARDS, cardiogenic pulmonary edema, pneumothorax, and pneumonia are shown in Figures 2 and 3.

\section{Changes in Diagnosis}

Of the 108 ARF patients included in our study, etiological diagnosis of ARF was altered or modified after the CPUS in 40 (37\%) patients, which included "diagnosis changed" in 18 (17\%) and "diagnosis added" in 22 (20\%) patients (Flowchart 1).

Cases of "diagnosis changed" represented complete change in etiological diagnosis of ARF after US. In all these cases, primary treating intensivist's ICD was different from that suspected before US. This included five cases of cardiogenic pulmonary edema, four cases of ARDS, three cases of pneumothorax, three cases of consolidation, two cases of $\mathrm{PE}$, and one case of acute bronchospasm (decompensated COPD/acute asthma). Cases of "diagnosis added" represented cases where primary treating intensivist's ICD was correct, but some additional unsuspected finding/diagnosis had been added after US.

Table 4: Brief description of guidelines and tests used by the treating intensivists to established final diagnosis of ARF

\begin{tabular}{|c|c|c|}
\hline Diagnoses & No. of patients $(n)$ & Methods \\
\hline For all patients & \multicolumn{2}{|c|}{$\begin{array}{l}\text { History, clinical examination, chest radiographic and ultrasound data, the results of chest CT imaging }(n=49) \text {, } \\
\text { favorable clinical progression under treatment. }\end{array}$} \\
\hline Pneumonia & $n=34$ & $\begin{array}{l}\text { Infectious profile, microorganism isolated (bronchial aspirate, sputum and blood } \\
\text { culture), radiologic asymmetry, recovery with antibiotics. Included were infectious, aspi- } \\
\text { ration, community or hospital-acquired pneumonia, ventilator associated pneumonia. } \\
\text { Pneumonia complicating chronic respiratory disease was classified as pneumonia. }\end{array}$ \\
\hline $\begin{array}{l}\text { Hydrostatic or cardiogenic } \\
\text { pulmonary edema }\end{array}$ & $n=22$ & $\begin{array}{l}\text { Evaluation of biochemical tests (NT-proBNP, etc.), cardiac function using echocardiogra- } \\
\text { phy by cardiologist. }\end{array}$ \\
\hline $\begin{array}{l}\text { Nonhydrostatic pulmonary } \\
\text { edema or ARDS }\end{array}$ & $n=19$ & $\begin{array}{l}\text { Diagnosis of ARDS is based on fulfilling the Berlin definition criteria for timing of the } \\
\text { syndrome's onset, origin of edema, chest radiograph findings, hypoxemia and risk fac- } \\
\text { tors. Objective assessment (e.g., echocardiography) to exclude hydrostatic edema if no } \\
\text { risk factor identified. }\end{array}$ \\
\hline Pneumothorax & $n=12$ & $\begin{array}{l}\text { Multislice } \mathrm{CT} \text { (pneumothorax patients with pulmonary contusion were considered as } \\
\text { pneumothorax) }\end{array}$ \\
\hline $\begin{array}{l}\text { Acute bronchospasm } \\
\text { (decompensated COPD or } \\
\text { acute asthma) }\end{array}$ & $n=13$ & $\begin{array}{l}\text { Bronchospasm was confirmed by history, responds to bronchodilator treatment and } \\
\text { respiratory function tests if needed. }\end{array}$ \\
\hline Pulmonary embolism & $n=8$ & Plasma d-dimer levels, multislice CT pulmonary angiography (CTPA), \\
\hline \multirow[t]{4}{*}{ Excluded patients } & $n=15$ & $\begin{array}{l}\text { (a) No final diagnosis }(n=4) \text { : unknown diagnosis at the end of hospitalization }(n=2) \text {, } \\
\text { rapid deterioration and death preventing conclusions }(n=2) \text {. }\end{array}$ \\
\hline & & $\begin{array}{l}\text { (b) Multiple final diagnosis for ARF }(n=5) \text { : patients having multiples etiological diagno- } \\
\text { ses for ARF were excluded. }\end{array}$ \\
\hline & & $\begin{array}{l}\text { (c) Miscellaneous diagnoses }(n=2) \text { massive pleural effusion }(n=1) \text {, glottic edema }(n= \\
\text { 1), }\end{array}$ \\
\hline & & $\begin{array}{l}\text { (d) US incomplete or not done (4): US was incomplete or not done due to a thoracotomy } \\
\text { wound, subcutaneous emphysema, or inadequate sonographic window. }\end{array}$ \\
\hline
\end{tabular}




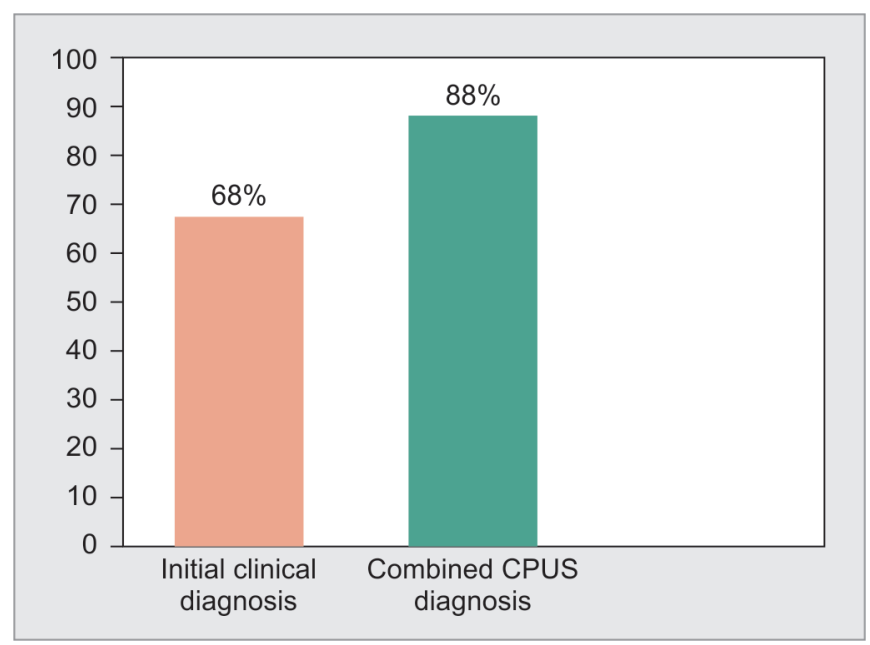

Fig. 1: Bar diagram showing comparative diagnostic accuracy: initial clinical diagnosis and combined cardiopulmonary ultrasound (CPUS) diagnosis yielded a correct etiological diagnosis for acute respiratory failure (ARF) in $68 \%$ and $88 \%$ cases respectively as compared against the final diagnosis

\section{Changes in Treatment Plan}

After combined US, treatment plan changed in 39 (36\%) patients (Flowchart 2). Among the surgical interventions thoracentesis under US guidance was done in $17(16 \%)$ patients; ICT was placed for pneumothorax in 5 patients; and 1 procedure (ICT placement) was cancelled based on the US results. Ventilation strategy changed in four (3.5\%) patients, which included two cases where lung protective IMV started for ARDS and two cases of escalation from NIV to IMV. Changes in medical therapy was made in $12(11 \%)$ patients which included fluid restriction in 3 $(2.5 \%)$, fluid restriction plus addition of diuretics in $3(2.5 \%)$, fluid restriction plus addition of inotropes in $2(2 \%)$, only inotropes addition in 2 (2\%), and only diuretics addition in 1 (1\%). Most of changes in medical therapy occurred in patients with cardiogenic pulmonary edema. Anticoagulants had to be started in two (2\%) cases for treatment of PE, not suspected in initial clinical assessment.

\section{Transthoracic Echocardiography}

Of the 108 included patients, echocardiographic findings were LV dysfunction in 34 (31.5\%), RV dysfunction in 8 (7.5\%), biventricular dysfunction in $3(3 \%)$, and isolated pericardial effusion (without ventricular dysfunction) in $6(5 \%)$ patients. Among the patients with LV dysfunction, 16 (15\%) had both LV diastolic and systolic dysfunction, 15 (14\%) had only LV systolic dysfunction (LVEF $<50 \%)$ and 6 had only LV diastolic dysfunction. Overall 31 patients had LVEF $<50 \%$, of them 26 (24\%) had LVEF between 30 to $<50$ and 5 (5\%) patients had LVEF <30. Mitral regurgitation was detected in 21 (19\%) cases, of them 9 cases also showed evidence of mitral stenosis. Pericardial effusion was noted in 12 (11\%) patients.

\section{Discussion}

The main results of our study were (i) significant improvement in the diagnostic accuracy of early CPUS compared with usual care (i.e., physical examination, chest radiography, and emergency laboratory tests) for the etiological diagnosis of ARF in critically ill patient; and (ii) high incidence of change in clinician's initial diagnosis and
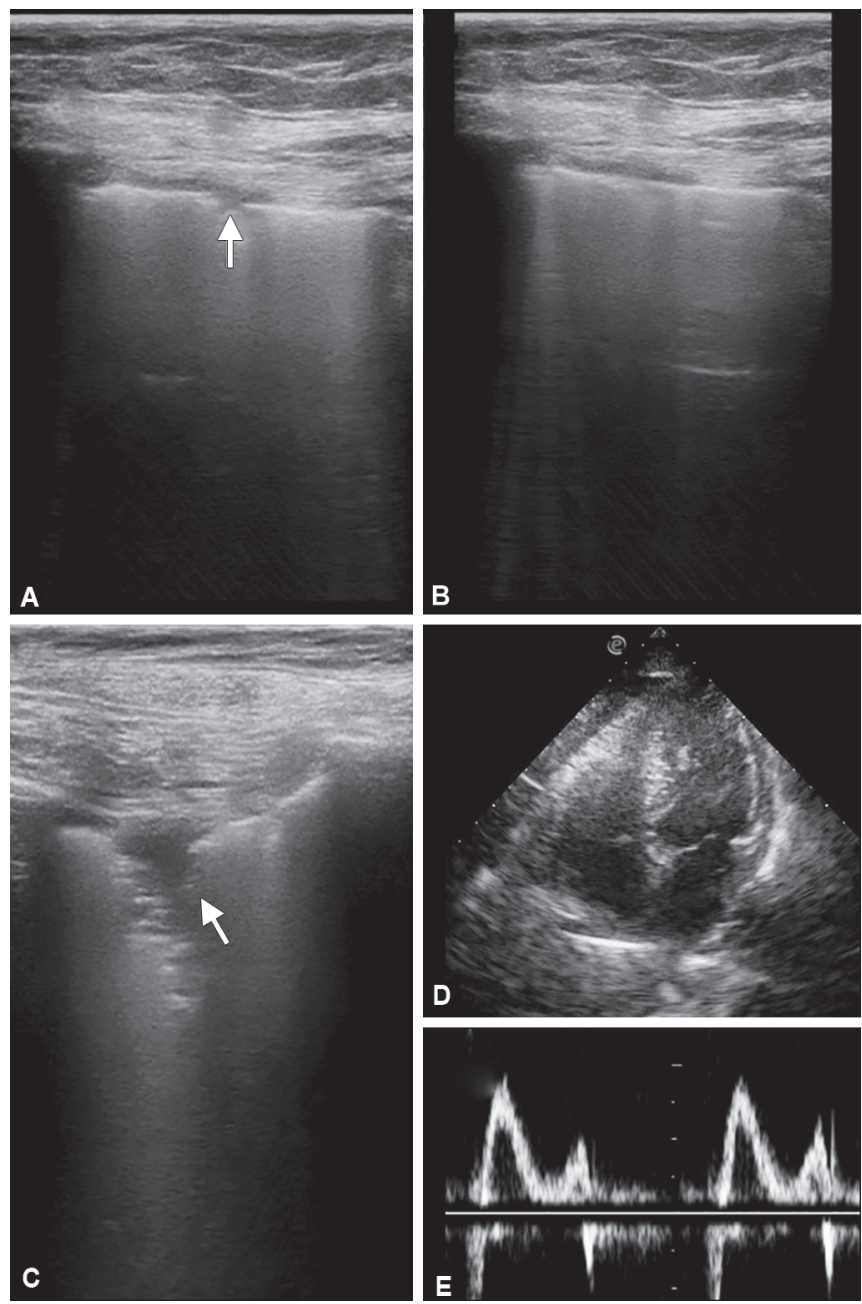

Figs 2A to E: Ultrasound findings in a case of ARDS: LUS ( $A$ to $C$ ) showing multiple confluent B-lines diffusely in bilateral lungs (B profile) with associated pleural line irregularities (white arrow) and subpleural consolidations (white arrow); TTE ( $D$ and E) from the same patient showed normal LVEF and normal mitral inflow pattern (PW Doppler image)

treatment after early CPUS in critically ill patient with ARF indicating significant impact of CPUS on management of ARF patients. While most of the previous studies on critical care ultrasonography in ARF focused on diagnostic efficacy; only few studies ${ }^{13,17,35}$ evaluated the therapeutic impact of a combined ultrasonography approach in critically ill patients.

In our study, among the 108 included patients with ARF, CPUS test yielded a correct etiological diagnosis in $88 \%$ of ARF cases, whereas primary treating intensivists' ICD was correct only in $68 \%$ of ARF cases. The higher accuracy of CPUS over clinical examination and CXR is supported by results of previous studies. ${ }^{10,16,25}$ Furthermore, higher diagnostic accuracy of the early combined CPUS approach was found when six main etiological entities of ARF were analyzed independently. We found similar sensitivity and specificity as were described in previous studies using combined CPUS for etiological diagnosis of ARF in critical care. ${ }^{13,14}$

Our data showed that ICD of ARF (made before US scan) was altered in $37 \%$ cases after sharing combined CPUS findings with the treating intensivists. This included $17 \%$ cases, where ICD was changed to a different type or previously unsuspected pathology; and $20 \%$ cases, where some additional finding had been added after 

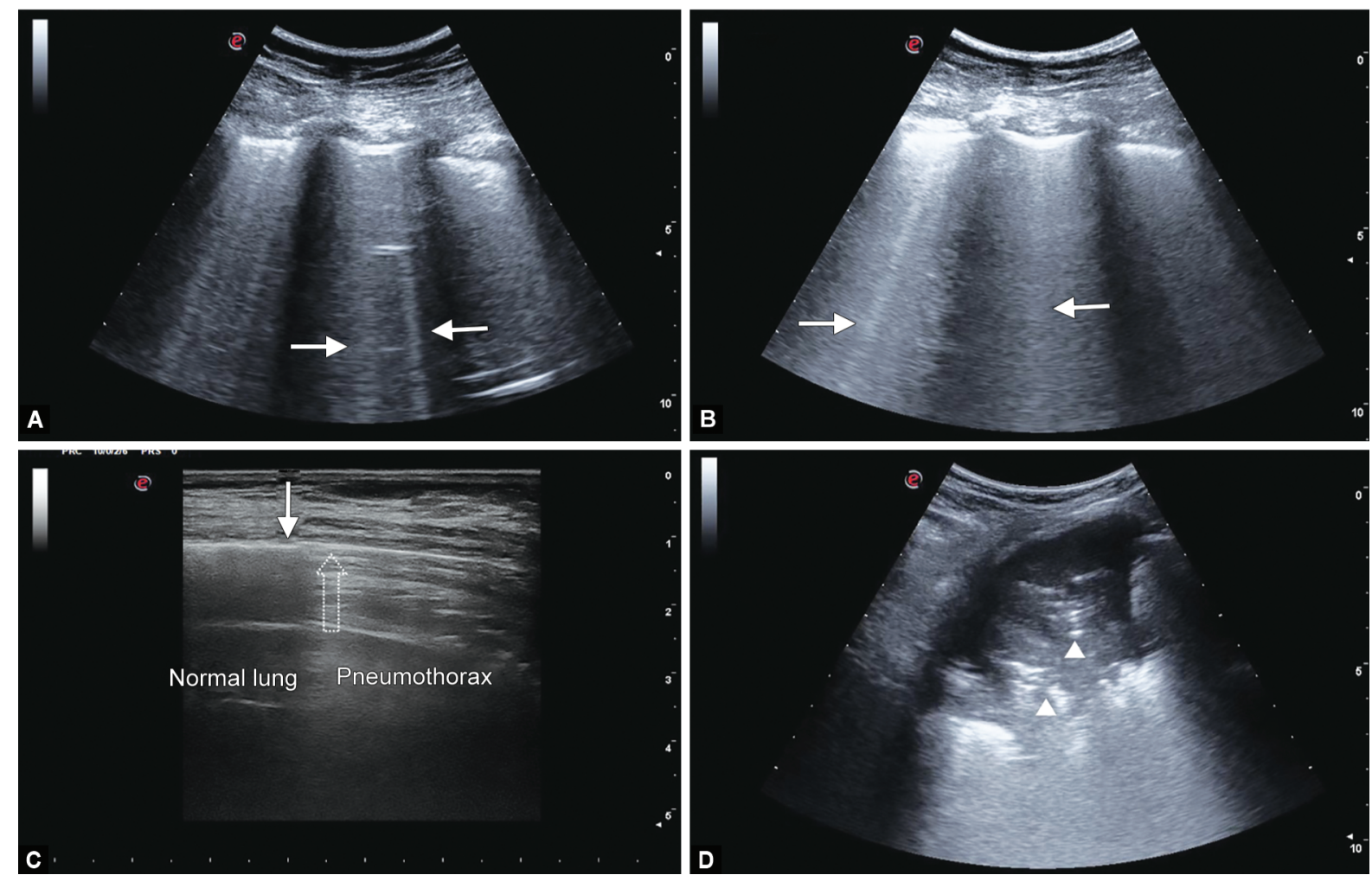

Figs 3A to D: (A and B) Lung ultrasound (LUS) in a case of cardiogenic pulmonary edema showing multiple B-lines in bilateral anterior lung regions diffusely; (C) LUS in a case of pneumothorax showing the lung point which is a transition point between lung parenchyma (solid arrow) and pneumothorax (dashed arrow); (D) LUS in a case of pneumonia showing alveolar consolidation as subpleural hypoechoic region or tissue-like echotexture (C profile) with air bronchograms (white arrowheads)

Flowchart 1: Changes in etiological diagnosis of ARF after CPUS. Data represents n (\%). "Diagnosis changed" represented cases where the ICD (made before US) was completely different from the modified diagnosis made by the treating intensivist after US test; and indicated complete change in etiological diagnosis of ARF. "Diagnosis added" represented cases where the ICD was part of modified diagnosis (made by the treating intensivist after US), but some additional finding/diagnosis had been added after ultrasound test

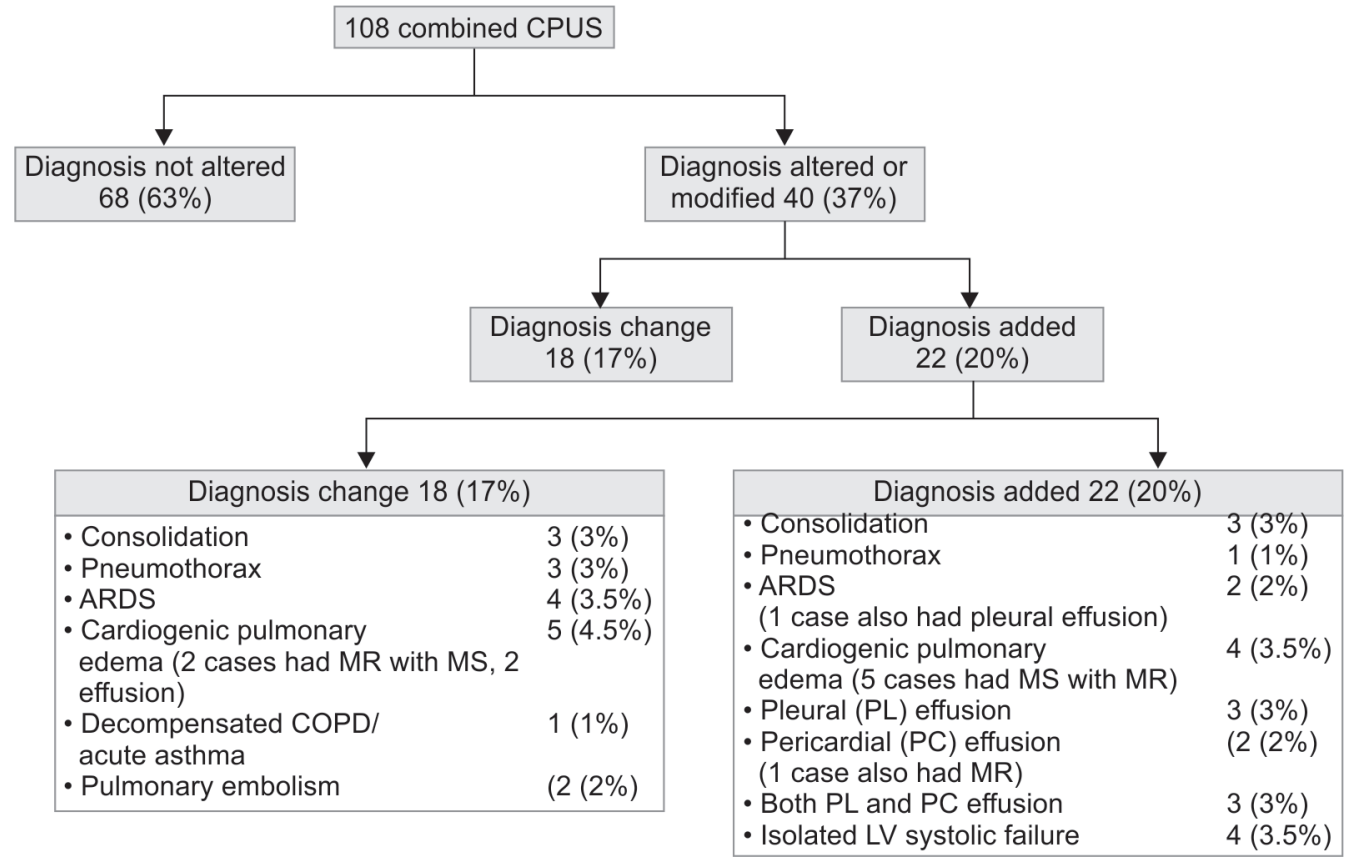


Flowchart 2: Changes in treatment plan after combined focused lung and heart ultrasound. Data represents $\mathrm{n}$ (\%). "Lung protective ventilation" in ARDS represents mechanical ventilation using lower tidal volumes, lower inspiratory pressures, prone positioning and alveolar recruitment options by higher PEEP levels. ICT, intercostal chest tube; IMV, invasive mechanical ventilation; NIV, noninvasive ventilation

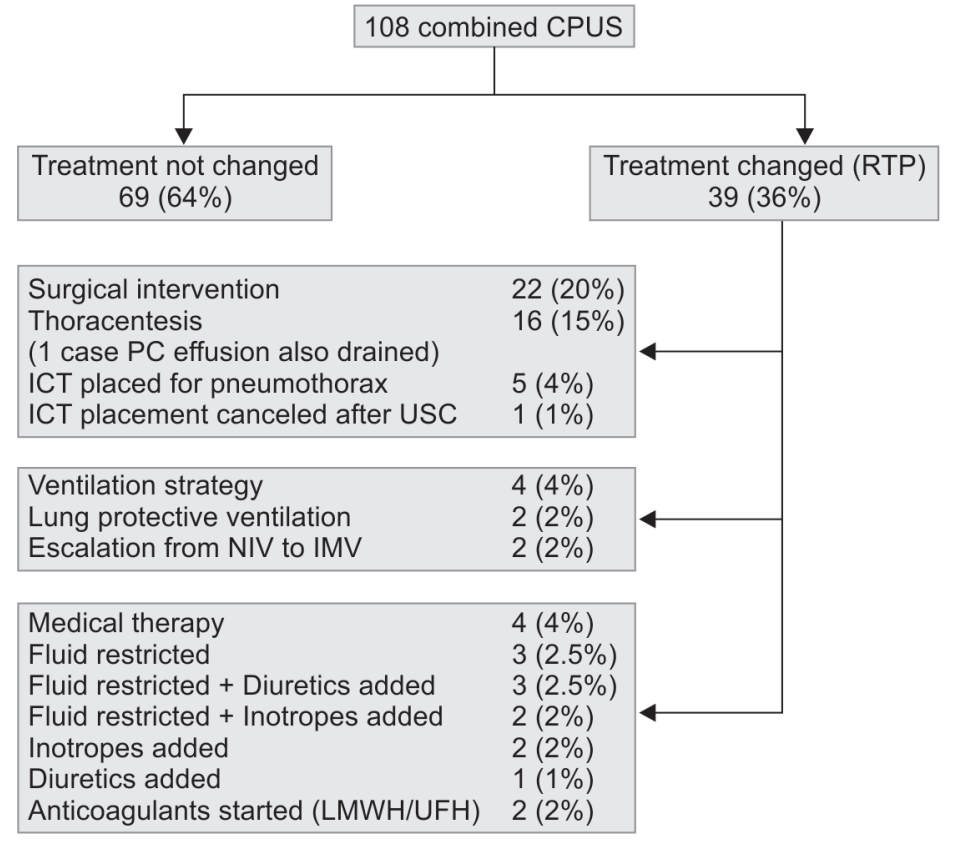

US test. Most of these cases were cardiogenic pulmonary edema and ARDS. This can be justified as previous studies have shown low accuracy of physical examination and bedside CXR compared to US for detection of origin of pulmonary edema. ${ }^{10,13,19,25}$ In few patients in our study, pneumothorax, consolidation, $\mathrm{PE}$, and pleural and pericardial effusions were missed by the treating intensivists on clinical evaluation. These changes in diagnosis cautioned the treating intensivist and in some cases triggered a change in treatment plan, while in cases, where there was concordance in CPUS and ICD, the intensivists were reassured.

In our study, CPUS test resulted in a change of treatment plan in about $36 \%$ of patients. CPUS scan led to drainage of pleural effusion in significant percentage of patients (15\%), and change in ventilation strategy in a small proportion of patients (4\%). Most of the changes in medical therapy occurred in patients, when cardiogenic pulmonary edema (missed on clinical evaluation and (XR) was detected in CPUS. This type of change in diagnosis and treatment has been reported in few previous studies in ICU setting ${ }^{16,17,39}$ as well as in anesthetic preoperative assessment and emergency setting. ${ }^{40,41}$ However, our results are specific for ARF patients, which has been lacking in most of the previous studies.

Our data suggest that lung ultrasonography provides quick assessment of common etiologies of ARF but addition of cardiac US helps in accurate differentiation of some pathological factors, having somewhat similar pattern in LUS. For example, both cardiogenic pulmonary edema and ARDS show diffuse bilateral B-lines pattern on LUS but addition of cardiac US helps in differentiating between them. This is in agreement with previous studies $^{13,14}$ that showed combined CPUS is more accurate in differentiating ARDS from cardiogenic pulmonary edema and, in disagreement with previous studies ${ }^{12,25}$ suggesting that lung ultrasonography without echocardiography could be used to estimate cardiogenic pulmonary edema. Our study highlights the potential limitations of isolated LUS and provides a comprehensive and feasible diagnostic alternative by combining LUS and TTE. Our data also show that CPUS findings suggestive of PE in the absence of other lung pathology in ARF may alert the treating clinician, and assist in diagnosis, risk stratification, and management.

Our study has some limitations. Firstly, interobserver variability could not be assessed as single operator did all US scans. However, the investigator had 1 year of experience in ultrasonography, took supervised training in critical care ultrasonography; and followed a standard predefined algorithm. Secondly, we evaluated LVEF and mitral valve disease based on visual assessment; however, we did not calculate LVEF and mitral valve area. So, it might be possible that we were not able to diagnose mild changes in LVEF and mild mitral stenosis. Thirdly, patients with multiple etiological diagnoses for ARF such as ARDS plus congestive heart failure were subsequently excluded. The reference standard was final diagnosis on patient assessment file. Although a team comprising of three senior intensivists established the FD, there could have been diagnostic errors. Finally, it is possible that changes in diagnosis and treatment plan, which occurred after US, may have occurred without US. The treating intensivist may have changed diagnosis and treatment based on response to treatment, or after internal discussion with other intensivists.

Despite these limitations, our study has several advantages. Our study shows that addition of combined US approach as a supplement to clinical evaluation not only improves the diagnostic accuracy but also changes diagnosis and treatment plan in significant proportion of ARF cases. Feasibility was demonstrated, as investigator was able to obtain interpretable images in the majority of patients.

\section{ConClusion}

This study demonstrates that use of combined US approach (CPUS and targeted venous US) as an initial test in ARF improves diagnostic accuracy for identification of underlying etiology and frequently changes clinical diagnosis and/or treatment. We conclude that routine screening of ARF patients at admission to ICU with 
combined US approach is feasible and has significant diagnostic as well as therapeutic impact.

\section{ACKNOWLedgments}

The authors thank Syed N Muzaffar, Suhail S Siddiqui, Sulekha Saxena, Armin Ahmed (Department of Critical Care Medicine, King George's Medical University) for their support and assistance. The authors also acknowledge the patients and/or their family members that agreed to participate in this study.

\section{References}

1. International Classification of Diseases and Related Health Problems, 10th Revision (ICD-10). Respiratory failure, 2018, https://www. icd10data.com/ICD10CM/Codes/J00-J99/J96-J99/J96-/J96.0.

2. Vincent J-L, Akça S, de Mendonça A, Haji-Michael P, Sprung C, Moreno $\mathrm{R}$, et al. The epidemiology of acute respiratory failure in critically ill patients. Chest 2002;121(5):1602-1609. DOI: 10.1378/chest.121.5.1602.

3. Vincent JL, Sakr Y, Ranieri VM. Epidemiology and outcome of acute respiratory failure in intensive care unit patients. Crit Care Med 2003;31(Supplement):S296. DOI: 10.1097/01. CCM.0000057906.89552.8F.

4. Rezoagli E, Fumagalli R, Bellani G. Definition and epidemiology of acute respiratory distress syndrome. Ann Transl Med 2017;5(14):282. DOI:10.21037/atm.2017.06.62.

5. Neto AS, Barbas CSV, Simonis FD, Artigas-Raventós A, Canet J, Determann RM, et al. Epidemiological characteristics, practice of ventilation, and clinical outcome in patients at risk of acute respiratory distress syndrome in intensive care units from 16 countries (PRoVENT): an international, multicentre, prospective study. Lancet Respir Med 2016;4(11):882-893. DOI: 10.1016/S2213-2600(16)30305-8.

6. Laffey JG, Madotto F, Bellani G, Pham T, Fan E, Brochard L, et al. Geo-economic variations in epidemiology, patterns of care, and outcomes in patients with acute respiratory distress syndrome: insights from the LUNG SAFE prospective cohort study. Lancet Respir Med 2017;5(8):627-638. DOI: 10.1016/S2213-2600(17)30213-8.

7. Sharma S, Gupta A, Biswas A, Sharma A, Malhotra A, Prasad KT, et al. Aetiology, outcomes \& predictors of mortality in acute respiratory distress syndrome from a tertiary care centre in north India. Indian J Med Res 2016;143(6):782-792. DOI: 10.4103/0971-5916.192063.

8. Narendra DK, Hess DR, Sessler CN, Belete HM, Guntupalli KK, Khusid $\mathrm{F}$, et al. Update in management of severe hypoxemic respiratory failure. Chest 2017;152(4):867-879. DOI: 10.1016/j.chest.2017.06.039.

9. Inglis AJ, Nalos M, Sue K-H, Hruby J, Campbell DM, Braham RM, et al. Bedside lung ultrasound, mobile radiography and physical examination: a comparative analysis of diagnostic tools in the critically ill. Crit Care Resusc J Australas Acad Crit Care Med 2016;18:124

10. Lichtenstein D, Goldstein I, Mourgeon E, Cluzel P, Grenier P, Rouby $\mathrm{J}$-J. Comparative diagnostic performances of auscultation, chest radiography, and lung ultrasonography in acute respiratory distress syndrome. Anesthesiology 2004;100(1):9-15. DOI: 10.1097/00000542200401000-00006.

11. Sood P, Paul G, Puri S. Interpretation of arterial blood gas. Indian J Crit Care Med Peer-Rev Off Publ Indian Soc Crit Care Med 2010;14:57-64.

12. Lichtenstein DA, Mezière GA. Relevance of lung ultrasound in the diagnosis of acute respiratory failure: The BLUE protocol. Chest 2008;134(1):117-125. DOI: 10.1378/chest.07-2800.

13. Silva S, Biendel C, Ruiz J, Olivier M, Bataille B, Geeraerts T, et al. Usefulness of cardiothoracic chest ultrasound in the management of acute respiratory failure in critical care practice. Chest 2013;144(3):859-865. DOI: 10.1378/chest.13-0167.

14. Bataille B, Riu B, Ferre F, Moussot PE, Mari A, Brunel E, et al. Integrated use of bedside lung ultrasound and echocardiography in acute respiratory failure: a prospective observational study in ICU. Chest 2014;146(6):1586-1593. DOI: 10.1378/chest.14-0681.
15. Stefan MS, Shieh M-S, Pekow PS, Rothberg MB, Steingrub JS, Lagu $T$, et al. Epidemiology and outcomes of acute respiratory failure in the United States, 2001 to 2009: a national survey. J Hosp Med 2013;8(2):76-82. DOI: 10.1002/jhm.2004.

16. Xirouchaki N, Magkanas E, Vaporidi K, Kondili E, Plataki M, Patrianakos $A$, et al. Lung ultrasound in critically ill patients: comparison with bedside chest radiography. Intensive Care Med 2011;37(9):1488-1493. DOI: 10.1007/s00134-011-2317-y.

17. Haji K, Haji D, Canty DJ, Royse AG, Tharmaraj D, Azraee M, et al. The Feasibility and impact of routine combined limited transthoracic echocardiography and lung ultrasound on diagnosis and management of patients admitted to ICU: a prospective observational study. J Cardiothorac Vasc Anesth 2018;32(1):354-360. DOI: 10.1053/j.jvca.2017.08.026.

18. Volpicelli G, Elbarbary M, Blaivas M, Lichtenstein DA, Mathis G, Kirkpatrick AW, et al. International evidence-based recommendations for point-of-care lung ultrasound. Intensive Care Med 2012;38(4):577591. DOI: 10.1007/s00134-012-2513-4.

19. Volpicelli G, Mussa A, Garofalo G, Cardinale L, Casoli G, Perotto F, et al. Bedside lung ultrasound in the assessment of alveolar-interstitial syndrome. Am J Emerg Med 2006;24(6):689-696. DOI: 10.1016/j. ajem.2006.02.013.

20. Chavez MA, Shams N, Ellington LE, Naithani N, Gilman RH, Steinhoff $M C$, et al. Lung ultrasound for the diagnosis of pneumonia in adults: a systematic review and meta-analysis. Respir Res 2014;15(1):50. DOI: 10.1186/1465-9921-15-50.

21. Hew M, Corcoran JP, Harriss EK, Rahman NM, Mallett S. The diagnostic accuracy of chest ultrasound for CT-detected radiographic consolidation in hospitalised adults with acute respiratory failure: a systematic review. BMJ Open 2015;5(5):e007838. DOI: 10.1136/ bmjopen-2015-007838.

22. Lui JK, Banauch Gl. Diagnostic bedside ultrasonography for acute respiratory failure and severe hypoxemia in the medical intensive care unit: basics and comprehensive approaches. J Intensive Care Med 2017;32(6):355-372. DOI: 10.1177/0885066616658475.

23. Al Deeb M, Barbic S, Featherstone R, Dankoff J, Barbic D. Point-of-care ultrasonography for the diagnosis of acute cardiogenic pulmonary edema in patients presenting with acute dyspnea: a systematic review and meta-analysis. Acad Emerg Med Off J Soc Acad Emerg Med 2014;21(8):843-852. DOI: 10.1111/acem.12435.

24. Martindale JL, Wakai A, Collins SP, Levy PD, Diercks D, Hiestand BC, et al. Diagnosing acute heart failure in the emergency department: a systematic review and meta-analysis. Acad Emerg Med Off $J$ Soc Acad Emerg Med 2016;23(3):223-242. DOI: 10.1111/acem. 12878.

25. Copetti R, Soldati G, Copetti P. Chest sonography: a useful tool to differentiate acute cardiogenic pulmonary edema from acute respiratory distress syndrome. Cardiovasc Ultrasound 2008;6(1):16. DOI: 10.1186/1476-7120-6-16.

26. Wallbridge $P$, Steinfort $D$, Tay TR, Irving L, Hew M. Diagnostic chest ultrasound for acute respiratory failure. Respir Med 2018;141:26-36. DOI: 10.1016/j.rmed.2018.06.018.

27. Kumar S, Agarwal R, Aggarwal AN, Gupta D, Jindal SK. Role of ultrasonography in the diagnosis and management of pneumothorax following transbronchial lung biopsy. J Bronchol Interv Pulmonol 2015:22(1):14-19. DOI: 10.1097/LBR.0000000000000125.

28. Ebrahimi A, Yousefifard M, Mohammad Kazemi H, Rasouli HR, Asady H, Jafari AM, et al. Diagnostic accuracy of chest ultrasonography versus chest radiography for identification of pneumothorax: a systematic review and meta-analysis. Tanaffos 2014;13:29-40.

29. Alrajhi K, Woo MY, Vaillancourt C. Test characteristics of ultrasonography for the detection of pneumothorax: a systematic review and meta-analysis. Chest 2012;141(3):703-708. DOI: 10.1378/ chest.11-0131.

30. Lichtenstein $D$, Mezière $G$, Biderman $P$, Gepner $A$. The "lung point": an ultrasound sign specific to pneumothorax. Intensive Care Med 2000;26(10):1434-1440. DOI: 10.1007/s001340000627. 
31. Squizzato A, Rancan E, Dentali F, Bonzini M, Guasti L, Steidl L, et al. Diagnostic accuracy of lung ultrasound for pulmonary embolism: a systematic review and meta-analysis. J Thromb Haemost JTH 2013;11(7):1269-1278. DOI: 10.1111/jth.12232.

32. Jiang L, Ma Y, Zhao C, Shen W, Feng X, Xu Y, et al. Role of transthoracic lung ultrasonography in the diagnosis of pulmonary embolism: a systematic review and meta-analysis [internet]. PLoS ONE 2015. 10. Available from: https://www.ncbi.nlm.nih.gov/pmc/articles/ PMC4468196/.

33. Acar H, Yılmaz S, Yaka E, Doğan NÖ, Özbek AE, Pekdemir M. Evaluation of the diagnostic role of bedside lung ultrasonography in patients with suspected pulmonary embolism in the emergency department. Balk Med J 2017;34:356-361. DOI: 10.4274/balkanmedj.2016. 1181.

34. Nazerian P, Vanni S, Volpicelli G, Gigli C, Zanobetti M, Bartolucci M, et al. Accuracy of point-of-care multiorgan ultrasonography for the diagnosis of pulmonary embolism. Chest 2014;145(5):950-957. DOI: 10.1378/chest.13-1087.

35. Manno E, Navarra M, Faccio L, Motevallian M, Bertolaccini L, Mfochivè A, et al. Deep impact of ultrasound in the intensive care unit: the "ICUsound" protocol. Anesthesiology 2012;117(4):801-809. DOI: 10.1097/ ALN.0b013e318264c621.

36. Nagueh SF, Appleton CP, Gillebert TC, Marino PN, Oh JK, Smiseth $\mathrm{OA}$, et al. Recommendations for the evaluation of left ventricular diastolic function by echocardiography. J Am Soc Echocardiogr Off Publ Am Soc Echocardiogr 2009;22(2):107-133. DOI: 10.1016/j. echo.2008.11.023.

37. Pandompatam G, Sweeney DA, Diaz-Gomez JL, Wiley BM. Integrated cardiac and lung ultrasound (ICLUS) in the cardiac intensive care unit. Curr Cardiovasc Imaging Rep 2018;11(9):23. DOI: 10.1007/s12410-0189463-3.

38. Levitov A, Frankel HL, Blaivas M, Kirkpatrick AW, Su E, Evans D, et al. Guidelines for the appropriate use of bedside general and cardiac ultrasonography in the evaluation of critically ill patients-part II: Cardiac ultrasonography. Crit Care Med 2016;44(6):1206-1227. DOI: 10.1097/CCM.0000000000001847.

39. Bernier-Jean A, Albert M, Shiloh A, Lewis E, Jennifer H, David W, et al. 250: The diagnostic and therapeutic impact of point-of-care ultrasonography in the intensive care unit. Crit Care Med 2012;40:1. DOI: $10.1097 / 01 . c c m .0000424468 .49504 .83$.

40. Canty DJ, Royse CF, Kilpatrick D, Bowman L, Royse AG. The impact of focused transthoracic echocardiography in the pre-operative clinic. Anaesthesia 2012;67(6):618-625. DOI: 10.1111/j.13652044.2012.07074.x.

41. Yates J, Royse CF, Royse C, Royse AG, Canty DJ. Focused cardiac ultrasound is feasible in the general practice setting and alters diagnosis and management of cardiac disease. Echo Res Pract 2016;3(3):63-69. DOI: 10.1530/ERP-16-0026. 